\title{
Hydrogen Retention Behavior in Boron Films Affected by Impurities Introduced by Hydrogen Plasma Exposure in the LHD*)
}

\author{
Katsushi MATSUOKA, Makoto KOBAYASHI, Kiyotaka KAWASAKI, Tetsuo FUJISHIMA, \\ Yuto MIYAHARA, Naoko ASHIKAWA ${ }^{1)}$, Kiyohiko NISHIMURA ${ }^{1)}$, Akio SAGARA $^{1)}$, \\ Yasuhisa OYA and Kenji OKUNO \\ Radioscience Research Laboratory, Faculty of Science, Shizuoka University, \\ 836 Ohya, Suruga-ku, Shizuoka 422-8529, Japan \\ 1)National Institute for Fusion Science, 322-6 Oroshi-cho, Toki-shi, Gifu 509-5292, Japan
}

(Received 30 November 2011 / Accepted 7 November 2012)

\begin{abstract}
The chemical states of impurities such as oxygen and carbon and their effects on hydrogen retention behavior in pure boron films exposed to hydrogen plasma in the Large Helical Device were investigated by X-ray photoelectron spectroscopy and thermal desorption spectroscopy. The atomic concentrations of the boron films after hydrogen plasma exposure changed from $94 \% \mathrm{~B}, 4 \% \mathrm{C}$, and $2 \% \mathrm{O}$ to $68 \% \mathrm{~B}, 20 \% \mathrm{C}$, and $12 \% \mathrm{O}$. B-C bonds and free oxygen were the major chemical states of impurities in the boron films after hydrogen plasma exposure. The hydrogen isotope retention behavior of a hydrogen-plasma-exposed boron film and a $\mathrm{D}_{2}^{+}$-implanted one clearly differed, and the retention of hydrogen as $\mathrm{B}-\mathrm{H}$ bonds was reduced by hydrogen plasma exposure owing to the chemical sputtering of hydrogen with free oxygen. In addition, the hydrogen desorption stage was observed as B-C-H bonds at approximately $900 \mathrm{~K}$, although the amount of retention as B-C-H bonds was $10 \%$ of the total for a pure boron film exposed to hydrogen plasma.
\end{abstract}

(C) 2012 The Japan Society of Plasma Science and Nuclear Fusion Research

Keywords: hydrogen plasma, hydrogen retention, boronization, oxygen, carbon

DOI: $10.1585 /$ pfr.7.2401157

\section{Introduction}

Boronization has been applied as a wall conditioning technique to remove impurities such as carbon and oxygen in plasma of the Large Helical Device (LHD) at the National Institute for Fusion Science (NIFS). Impuritycontaining boron films are thought to form on the first wall during boronization [1-3]. One of the most important issues in the use of boronization is the elucidation of the hydrogen isotopes retention behavior interacting with the impurities introduced to the boron film by hydrogen plasma exposure. The interaction of energetic hydrogen isotopes with the impurity-containing boron films should be clarified to evaluate the tritium inventory in the LHD.

In our previous studies, the major chemical states of deuterium trapped in the boron film were B-D-B and B$\mathrm{D}$ bonds [4]. Additional desorption stages of deuterium trapped as B-O-D [5] and B-C-D [6] bonds were observed with the addition of oxygen and carbon as impurities. The formation of heavy water $\left(\mathrm{D}_{2} \mathrm{O}\right)$ and/or hydrocarbons $\left(\mathrm{CD}_{\mathrm{x}}\right)$, which would prevent stable plasma operation in fusion devices, were promoted by energetic deuterium implantation. Hydrogen was also found to be trapped as $\mathrm{B}-\mathrm{H}-\mathrm{B}, \mathrm{B}-\mathrm{H}, \mathrm{B}-\mathrm{O}-\mathrm{H}$, and $\mathrm{B}-\mathrm{C}-\mathrm{H}$ bonds in boron films exposed to hydrogen plasma in the LHD. In addition, the

author'se-mail: srkokun@ipc.shizuoka.ac.jp

*) This article is based on the presentation at the 21st International Toki Conference (ITC21). atomic concentrations of the boron films changed from $75 \% \mathrm{~B}, 15 \% \mathrm{C}$, and $8 \% \mathrm{O}$ to $54 \% \mathrm{~B}, 19 \% \mathrm{C}$, and $23 \%$ $\mathrm{O}$ by hydrogen plasma exposure. The hydrogen retention behavior is expected to change with the addition of oxygen and carbon impurities by hydrogen plasma exposure.

In this study, pure boron films without impurities prepared by the plasma-assisted chemical vapor deposition (PCVD) apparatus at Shizuoka University were exposed to hydrogen plasma in the LHD in order to clarify the effects of oxygen and carbon impurities on the hydrogen retention behavior in boron films during hydrogen plasma operation.

\section{Experimental}

The pure boron film was deposited on a Si substrate by the P-CVD apparatus at Shizuoka University [7]. Before deposition, the Si substrate was exposed to He plasma for 30 min to clean the sample surface. Decaborane $\left(\mathrm{B}_{10} \mathrm{H}_{14}\right)$ gas diluted by $\mathrm{He}$ gas was introduced into the P-CVD chamber as the material gas. Boronization was performed for $1 \mathrm{~h}$ by the glow discharge technique. The substrate temperature was maintained at $673 \mathrm{~K}$ during boronization. The thickness and roughness of the pure boron film were $450 \mathrm{~nm}$ and $\pm 2 \mathrm{~nm}$, respectively, as measured using an atomic force microscope (KEYENCE CORPORATION, VN-8010). The chemical composition was evaluated by X-ray photoelectron spectroscopy (XPS, ULVAC-PHI Inc., 
ESCA 1600 Series). The observed composition of the pure boron film was $94 \% \mathrm{~B}, 4 \% \mathrm{C}$, and $2 \%$ O. After characterization, samples were placed at the 4.5-low port of the LHD and exposed to 226 shots of hydrogen plasma [8]. The ion energy was $10-100 \mathrm{eV}$, and the temperature was less than $373 \mathrm{~K}$. Deuterium ions $\left(\mathrm{D}_{2}^{+}\right)$were implanted in other samples at room temperature with an ion energy of $1.0 \mathrm{keV} \mathrm{D}_{2}^{+}$ and a flux of $1.0 \times 10^{18} \mathrm{D}^{+} \mathrm{m}^{-2} \mathrm{~s}^{-1}$ up to a fluence of $1.0 \times$ $10^{22} \mathrm{D}^{+} \mathrm{m}^{-2}$.

After hydrogen plasma exposure or $\mathrm{D}_{2}^{+}$implantation for the pure boron films, the changes in their chemical states were measured by XPS without air exposure. The depth profiles of their chemical states were measured by a combination of XPS and $\mathrm{Ar}^{+}$sputtering. Thermal desorption spectroscopy (TDS) analysis was also performed from room temperature to $1173 \mathrm{~K}$ at a heating rate of $0.5 \mathrm{~K} \mathrm{~s}^{-1}$. The molecules desorbed from the samples were measured using a quadrupole mass spectrometer.

\section{Results and Discussion}

The atomic concentrations of the sample surface changed by hydrogen plasma exposure from $94 \%$ B, $4 \%$ $\mathrm{C}$, and $2 \% \mathrm{O}$ to $68 \% \mathrm{~B}, 20 \% \mathrm{C}$, and $12 \% \mathrm{O}$. The O- $1 \mathrm{~s}$ and C-1s XPS spectra of the sample before and after hydrogen plasma exposure are shown in Fig. 1. The O-1s XPS spectra consisted of three peaks, namely O-B bonds,
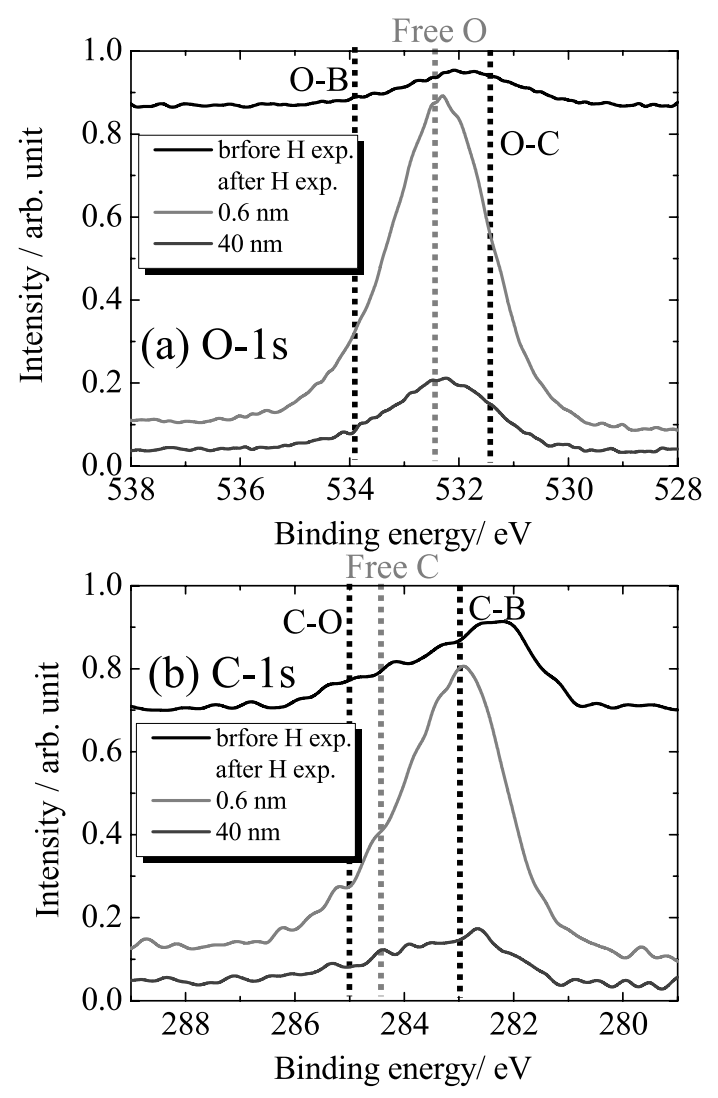

Fig. 1 Changes in (a) O-1s and (b) C-1s XPS spectra of the sample before and after hydrogen plasma exposure. free oxygen, and $\mathrm{O}-\mathrm{C}$ bonds, located at 534.0, 532.5, and $531.5 \mathrm{eV}$, respectively [9-12]. The C-1s XPS spectra indicated three chemical states, namely $\mathrm{C}-\mathrm{O}$ bonds, free carbon, and C-B bonds located at 285.0, 284.5, and $283.0 \mathrm{eV}$, respectively [13-15]. Here free oxygen or carbon is defined as an atom of oxygen or carbon, respectively, in a boron film $[12,15]$. The atomic concentrations and chemical states of the boron film at a depth of more than $40 \mathrm{~nm}$ were the same as those before hydrogen plasma exposure, indicating that oxygen and carbon introduced by the exposure diffused approximately $40 \mathrm{~nm}$ into the film. In addition, the major chemical states of oxygen and carbon introduced into the film by hydrogen plasma were free oxygen and $\mathrm{C}-\mathrm{B}$ bonds, respectively.

Figure 2 shows the depth profiles of the chemical states of oxygen and carbon in the sample after hydrogen plasma exposure. The vertical axis is normalized by the peak area of surface impurities. The major chemical states of oxygen and carbon from the surface to $40 \mathrm{~nm}$ were free oxygen and C-B bonds, respectively. Oxygen introduced by hydrogen plasma exposure existed mainly as free oxygen in the boron film, resulting in hydrogen release as $\mathrm{H}_{2} \mathrm{O}$ by sputtering during hydrogen plasma exposure. The amount of hydrogen released by sputtering was 2.08 $\times 10^{18} \mathrm{H} \mathrm{m}^{-2}$. This value was calculated using the amount of sputtered oxygen atoms assuming that the amount of oxygen reached equilibrium in the boron film.

On the other hand, the carbon impurities existed as
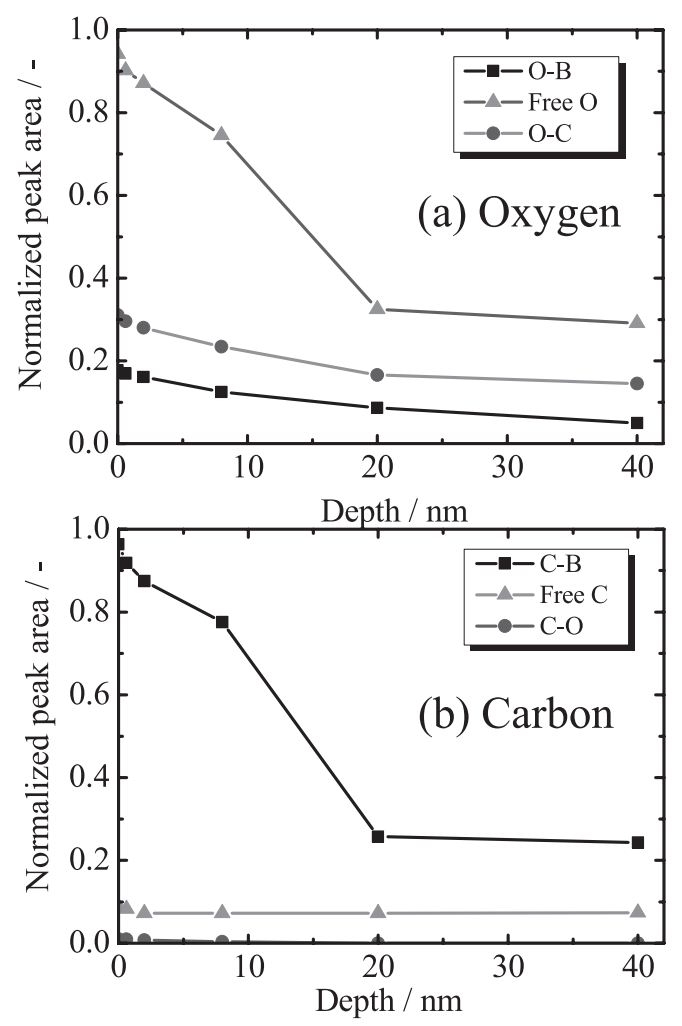

Fig. 2 Depth profiles of chemical states of (a) oxygen and (b) carbon in the sample exposed to hydrogen plasma. 


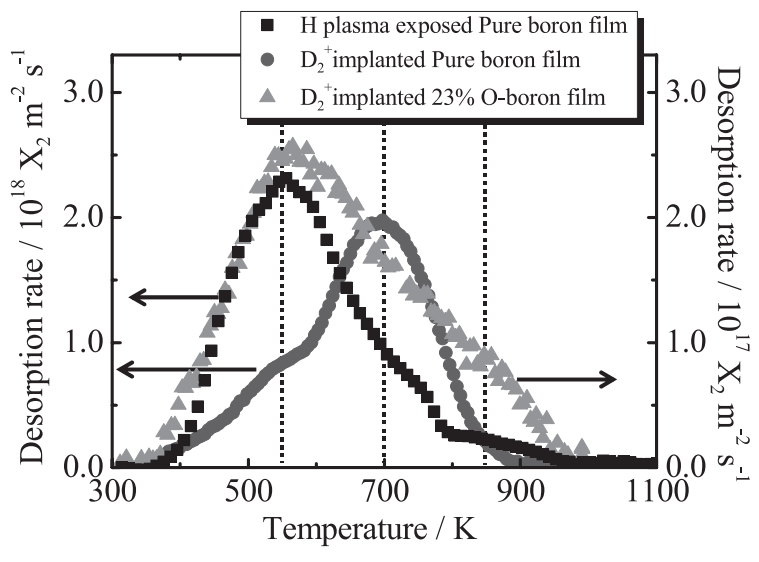

Fig. 3 TDS spectra for $\mathrm{D}_{2}^{+}$-implanted and hydrogen-plasmaexposed boron films and a $\mathrm{D}_{2}^{+}$-implanted boron film containing $23 \%$ oxygen.

C-B bonds. Carbon bound to boron as a terminal atom, which has dangling bonds, is known to be easily bound to hydrogen, and is believed to interact with hydrogen and cause the retention of hydrogen as $\mathrm{B}-\mathrm{C}-\mathrm{H}$ bonds.

The TDS spectra for $\mathrm{D}_{2}^{+}$-implanted and hydrogenplasma-exposed pure boron films and a $\mathrm{D}_{2}^{+}$-implanted boron film containing $23 \%$ oxygen are shown in Fig. 3. Three major hydrogen isotope desorption stages were observed in the three samples, namely Peaks 1, 2, and 3, located at approximately 550, 700, and $850 \mathrm{~K}$, respectively. Peaks 1 and 2 represented the desorption of deuterium retained as B-X-B and B-X bonds, respectively [4]. Peak 3 was identified as the desorption of hydrogen isotopes trapped by impurities. Here $\mathrm{X}$ indicates deuterium or hydrogen.

The hydrogen retention behavior clearly differed among these samples. A desorption peak at approximately $900 \mathrm{~K}$ was observed for the hydrogen-plasmaexposed pure boron film, indicating that the carbon impurities introduced by hydrogen plasma exposure would trap hydrogen to form $\mathrm{B}-\mathrm{C}-\mathrm{H}$ bonds, although the amount of retention as $\mathrm{B}-\mathrm{C}-\mathrm{H}$ bonds was $10 \%$ of the total for the pure boron film exposed to hydrogen plasma.

Figure 4 summarizes the hydrogen isotope retention ratio of each desorption stage for the hydrogen-plasmaexposed and $\mathrm{D}_{2}^{+}$-implanted pure boron films and the $\mathrm{D}_{2}^{+}$implanted pure boron film containing $23 \%$ oxygen [5].

The ratios of hydrogen retention desorbed as Peaks 1,2 , and 3 were similar in the hydrogen-plasma-exposed pure boron film and the $\mathrm{D}_{2}^{+}$-implanted boron film containing $23 \%$ oxygen. These samples had almost the same oxygen concentration. In oxygen-containing boron films, free oxygen would induce chemical sputtering by hydrogen isotopes, resulting in the desorption of hydrogen isotopes as water during energetic hydrogen isotope ion implantation [5]. Therefore, the hydrogen-plasma-exposed pure boron film was subject to chemical sputtering by hydrogen, and

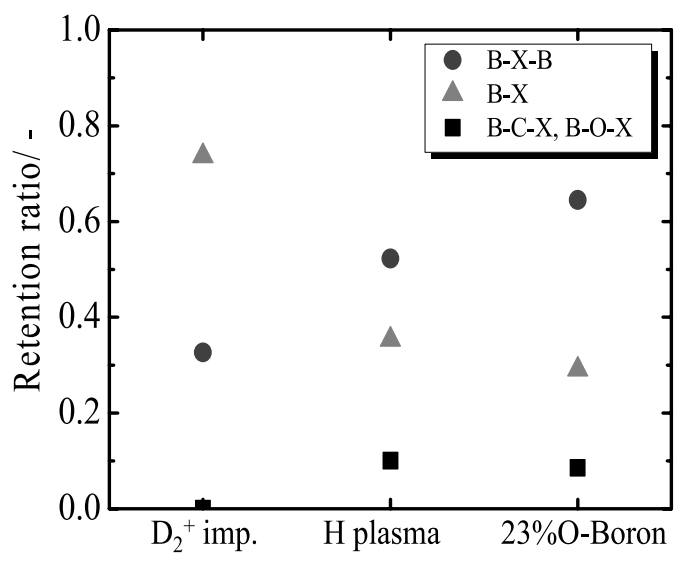

Fig. 4 Hydrogen isotope retention ratios of each desorption stage in hydrogen-plasma-exposed and $\mathrm{D}_{2}^{+}$-implanted pure boron films and a $\mathrm{D}_{2}^{+}$-implanted boron film containing $23 \%$ oxygen.

$\mathrm{H}_{2} \mathrm{O}$ was released during plasma exposure. In addition, the reconstitution of the amorphous boron structure and a decrease in hydrogen isotope trapping sites as B-D terminal bonds occurred in the boron films.

In long-term hydrogen plasma experiments, enhanced $\mathrm{H}_{2} \mathrm{O}$ release and increased hydrogen retention as $\mathrm{B}-\mathrm{C}-\mathrm{H}$ bonds are attributed to an increase in free oxygen and $\mathrm{B}-\mathrm{C}$ bonds, respectively, in the boron film.

\section{Conclusions}

The chemical states of impurities such as oxygen and carbon and their effects on the hydrogen retention behavior in pure boron films exposed to hydrogen plasma in the LHD were investigated by XPS and TDS. The XPS results indicated that carbon and oxygen were implanted in the boron films by hydrogen plasma exposure, changing their atomic concentration from $94 \% \mathrm{~B}, 2 \% \mathrm{O}$, and $4 \%$ $\mathrm{C}$ to $68 \% \mathrm{~B}, 12 \% \mathrm{O}$, and $20 \% \mathrm{C}$. Free oxygen and B-C bonds were the major chemical states of the impurities in the boron film after hydrogen plasma exposure. The TDS spectra showed that the hydrogen desorption profile of the hydrogen-plasma-exposed boron film clearly differed from that of the $\mathrm{D}_{2}^{+}$-implanted film and was similar to that of a $\mathrm{D}_{2}^{+}$-implanted oxygen-containing boron film, indicating that the behavior of hydrogen implanted in the boron film was controlled by the presence of free oxygen. The free oxygen reacted with hydrogen to form $\mathrm{H}_{2} \mathrm{O}$ by chemical sputtering. In addition, the reconstitution of the amorphous boron structure and a decrease in hydrogen isotope trapping sites existing as B-D terminal bonds occurred in the boron films. On the other hand, hydrogen retention as B$\mathrm{C}-\mathrm{H}$ bonds was caused by $\mathrm{C}-\mathrm{B}$ bond formation. Therefore, in long-term hydrogen plasma experiments, enhanced $\mathrm{H}_{2} \mathrm{O}$ release and increased hydrogen retention as $\mathrm{B}-\mathrm{C}-\mathrm{H}$ bonds are expected because of the increase in free oxygen and $\mathrm{B}-\mathrm{C}$ bonds, respectively, in the boron film. 


\section{Acknowledgments}

This study was supported by the NIFS collaboration

[6] S. Suzuki et al., J. Nucl. Mater. 390, 200 (2009).

[7] H. Kodama et al., J. Nucl. Mater. 329, 889 (2004).

program, NIFS07KLPP306, and the Center for Instrumental Analysis at Shizuoka University.

[1] N. Noda et al., J. Nucl. Mater. 266, 234 (1999).

[2] K. Nishimura et al., J. Nucl. Mater. 337, 431 (2005).

[3] K. Nishimura et al., J. Nucl. Mater. 79, 1216 (2003).

[8] Y. Nobuta et al., Fusion Eng. Des. 81, 187 (2006).

[9] H. Kemi et al., J. Nucl. Mater. 166, 1108 (1999).

[10] O.M. Moon et al., Thin. Sol. Fil. 464, 164 (2004).

[11] J. Anthony et al., Appl. Surf. Sci. 219, 317 (2003).

[12] R. Kessel et al., Surf. Interface Anal. 16, 401 (1990).

[13] L.G. Jacobsohn et al., Surf. Sci. 572, 418 (2004).

[4] M. Oyaidzu et al., Appl. Sur. Sci. 244, 240 (2005).

[14] I. Crassous et al., J. Fluorine Chem. 130, 1080 (2009).

[5] A. Yoshikawa et al., J. Nucl. Mater. 367, 1527 (2007).

[15] K.L. Smith et al., J. Vac. Sci. Technol. A2, 744 (1984). 